\title{
Temperature rise and initial shrinkage of alkali-activated fly ash cement pastes
}

\section{Julia Shekhovtsova}

PhD Student, Department of Civil Engineering, University of Pretoria, Pretoria, South Africa

Maxim Kovtun

Researcher, Department of Civil Engineering, University of Pretoria,

Pretoria, South Africa

\section{Elsabe P. Kearsley}

Professor, Head of Department of Civil Engineering, University of Pretoria, Pretoria, South Africa

This paper reports on core temperature development and initial shrinkage of fly ash cement pastes activated with sodium hydroxide solution at different concentrations during elevated-temperature curing at $60^{\circ} \mathrm{C}$. The results indicate that a high sodium hydroxide concentration might result in a substantial rise in the core temperature of samples, dependent on the mould size and ratio of paste to oven volume. An increase in alkali concentration was also found to increase the initial shrinkage of the pastes during elevated-temperature curing. Excessive initial shrinkage and temperature increase might lead to the appearance of internal stresses in the pastes, which can affect the material performance.

\section{Notation}

$H \quad$ initial sample height (m)

$H_{0} \quad$ initial laser reading $(\mu \mathrm{m})$

$H_{i} \quad$ laser reading at time $i(\mu \mathrm{m})$

$H_{\mathrm{m}} \quad$ depth of empty cone mould (m)

$H_{\mathrm{r}} \quad$ thickness of reflector (m)

$H_{\mathrm{t}} \quad$ distance from top of mould to reflector placed on the paste surface $(\mathrm{m})$

$L_{\mathrm{w}} \quad$ total mass loss (\%)

$m_{1} \quad$ mass of mould with paste before elevatedtemperature curing $(\mathrm{g})$

$m_{2} \quad$ mass of mould with sample after elevatedtemperature curing $(\mathrm{g})$ mass of empty mould (g)

$\begin{array}{ll}m_{\mathrm{m}} & \text { mass of empty mould } \\ T_{\mathrm{p}} & \text { peak temperature }\left({ }^{\circ} \mathrm{C}\right)\end{array}$

$t_{\mathrm{p}} \quad$ time of appearance of peak temperature after the start of elevated-temperature curing (min)

\section{Introduction}

Alkali-activated materials (geopolymers, alkali-activated fly ashes, slags) are a new type of binder that utilise industrial byproducts (fly ashes and slags), kaolin, rice husk ashes, different soils and so on (Bakharev et al., 1999; He et al., 2013; Hounsi et al., 2013; Steveson and Sagoe-Crentsil, 2005). The production of geopolymers results in lower carbon dioxide emissions, making these materials 'greener' than ordinary Portland cement (OPC) binders (McLellan et al., 2011; Papa et al., 2014; Turner and Collins, 2013; Van Deventer et al., 2010; Yang et al., 2013). Numerous studies have been devoted to alkali-activated materials (Bernal and Provis, 2014; Ismail et al., 2013; Palomo et al., 1999; Provis, 2013) and the problem of strength decreases for materials with a high alkali content is continuously raised in the literature (Criado et al., 2007; Fernández-Jiménez and Palomo, 2005; Heah et al., 2013; Provis, 2009; Somna et al., 2011; Sukmak et al., 2013; Van Jaarsveld and van Deventer, 1999). Heah et al. (2013) reported that the compressive strength of kaolin geopolymers decreased when a high concentration of sodium hydroxide was used, due to the excess of sodium ions $\left(\mathrm{Na}^{+}\right)$that weakened the material structure. Sukmak et al. (2013) reported that an excess of alkaline activator caused precipitation at a very early stage, before the condensation process, resulting in cracks on the fly ash particles. Some correlation between zeolite formation and decreased strength in geopolymers has been reported by Provis (2009) and Criado et al. (2007) reported that a high zeolite content prevents the attainment of high mechanical strength. Some researchers have noticed that increasing the sodium hydroxide concentration beyond an optimum point resulted in decreased strength of geopolymer paste due to early precipitation of aluminosilicate products on unreacted fly ash spheres (Somna et al., 2011), which could inhibit their activation (Fernández-Jiménez and Palomo, 2005). Van Jaarsveld and van Deventer (1999) also reported that an optimum ratio of sodium oxide/silicon dioxide or potassium oxide/silicon dioxide existed for the maximum compressive strength of fly ash based geopolymers: when this ratio is exceeded, excess alkali weakens the material structure, causing a negative impact on most physical properties. Shekhovtsova et al. (2014) found some correlation between strength decrease and microcrack formation in samples with high alkali dosages. There are 
thus multiple references to strength decreases caused by a high alkali content in the literature on fly ash geopolymers. However, it is still unclear how high alkali concentrations weaken the material structure or whether there is any other factor induced by a high alkali content that affects the compressive strength of alkali-activated materials.

It is known that the reaction of alkali activation of fly ash is exothermic (Palomo et al., 1999). However, the strength development of low-calcium fly ash based geopolymers is very slow at ambient temperatures (Puertas et al., 2000) and elevatedtemperature curing is normally used to accelerate the alkali activation process in order to gain adequate compressive strength at early ages (Alonso and Palomo, 2001a; Škvára et al., 2003; Winnefeld et al., 2010). The importance of heat evolution in OPC binders is well known: a large temperature rise due to the exothermal hydration process can lead to material cracking thereafter. Many parameters affect the heat evolution of OPC binder concretes, including fly ash replacement, superplasticiser dosage (Atiş, 2002) characteristics of the cement, initial material temperature, volume of poured concrete (Tarasov et al., 2010), which leads to the question of what happens to alkali-activated fly ash when it is exposed to medium-high temperatures. Numerous works on heat release measurements of different alkali-activated systems have been conducted (Alonso and Palomo, 2001b; Brough and Atkinson, 2002; Chithiraputhiran and Neithalath, 2013; FernándezJiménez and Puertas, 1997; Muñiz-Villareal et al., 2011; Palomo et al., 1999; Zhang et al., 2012). Zhang et al. (2013) reported that the heat release rate of metakaolin geopolymers increased monotonically with increasing sodium hydroxide concentration. However, even if the amount of heat released during alkali activation is known, the heat might dissipate into the surroundings or increase the temperature of the sample during elevated-temperature curing. Obviously, a large increase in temperature can damage the microstructure of the material and, as a result, can have an impact on its compressive strength and other properties. Temperatures widely used for alkali activation are as high as $60-80^{\circ} \mathrm{C}$, which probably would not cause damage of the microstructure of alkaliactivated fly ash. The cumulative heat from an oven combined with the internal heat from the alkali activation process might lead to a substantial rise of sample temperature and affect the newly formed material microstructure. After a review of the literature, no studies were found on how the heat released during the alkali activation process affects the core temperature development inside alkali-activated fly ash samples during elevated-temperature curing.

This work provides data on the core temperature development of sodium hydroxide activated fly ash pastes at $60^{\circ} \mathrm{C}$ temperature curing. The literature shows that different researchers used moulds of various sizes made from different materials to produce samples of alkali-activated pastes and mortars (Bakharev, 2005; Chindaprasirt et al., 2009; Criado et al.,
2012; Duxson et al., 2007; Ghosh and Ghosh, 2012; Görhan and Kürklü, 2014; Lemougna et al., 2014; Somna et al., 2011). In the work reported here, the effect of mould size and material on temperature development in the core of alkali-activated fly ash cement paste samples was investigated.

The alkali activation reaction of fly ash during elevatedtemperature curing is assumed to be accompanied by volume changes due to chemical reactions and water evaporation, which can possibly lead to the appearance of internal stresses and microcracks. Various studies have investigated the shrinkage performance of different alkali-activated systems (Atiş et al., 2009; Najafi Kani and Allahverdi, 2011; Ridtirud et al., 2011), but most were performed on hardened materials and basically demonstrated only drying shrinkage. Initial shrinkage, however, occurs immediately after casting and during elevated-temperature curing and this might be another reason for internal stresses and performance loss of alkali-activated fly ash cement pastes. In situ measurements of the initial shrinkage of alkali-activated fly ash cement pastes during elevatedtemperature curing were performed in this study utilising the shrinkage cone method (Eppers and Müller, 2010). This investigation will therefore add valuable knowledge to alkaliactivated fly ash systems and will improve understanding of the processes the material experiences during elevated-temperature curing.

\section{Experimental setup}

Materials

The fly ash used for this investigation was classified as having more than $80 \%$ of particles with a particle size of less than $45 \mu \mathrm{m}$ and with a density of $2200 \mathrm{~kg} / \mathrm{m}^{3}$. It was mainly amorphous with inclusions of crystalline quartz and mullite. The chemical composition of the fly ash is presented in Table 1 .

Sodium hydroxide flakes $(98 \cdot 5 \%$ purity) were dissolved in distilled water to obtain activator solutions, which were cooled to room temperature before mixing. The sodium hydroxide

\begin{tabular}{lc} 
Constituent & Content: wt \\
\hline Silicon dioxide $\left(\mathrm{SiO}_{2}\right)$ & $55 \cdot 8$ \\
Titanium dioxide $\left(\mathrm{TiO}_{2}\right)$ & $1 \cdot 6$ \\
Aluminium oxide $\left(\mathrm{Al}_{2} \mathrm{O}_{3}\right)$ & $30 \cdot 3$ \\
Iron oxide $\left(\mathrm{Fe}_{2} \mathrm{O}_{3}\right)$ & $3 \cdot 9$ \\
Magnesium oxide $(\mathrm{MgO})$ & $1 \cdot 1$ \\
Calcium oxide $(\mathrm{CaO})$ & $4 \cdot 1$ \\
Sodium oxide $\left(\mathrm{Na}_{2} \mathrm{O}\right)$ & $0 \cdot 2$ \\
Potassium oxide $\left(\mathrm{K}_{2} \mathrm{O}\right)$ & $0 \cdot 8$ \\
Phosphorus pentoxide $\left(\mathrm{P}_{2} \mathrm{O}_{5}\right)$ & 0.4 \\
Loss on ignition & 0.9
\end{tabular}

Table 1. Chemical composition of fly ash 
content of the alkali-activated fly ash cement pastes was calculated as the sodium oxide percentage of fly ash mass $(3 \%, 6 \%$, $9 \%, 12 \%$ and $15 \%)$.

\section{Mix designs and preparation}

Samples of alkali-activated fly ash cement pastes were prepared by mixing fly ash with activator solution in a pan mixer for $4 \mathrm{~min}$. The paste was transferred into moulds, vibrated for an appropriate time to remove air and then cured in an oven. The total amount of water was calculated to include both the amount of water necessary to produce sodium hydroxide (solid/flake) and distilled water added to produce alkaline solution. Binder solids were calculated as the sum of fly ash mass and sodium oxide. The water to binder solids ratio (w/s) was chosen to be as low as possible, and was kept constant at $0 \cdot 2$. Details of the mix designs and curing conditions are shown in Table 2.

\section{Test methods}

\section{Compressive strength}

Each mixture was cast into a plastic mould according to EN 196-1 (BSI, 2005). After elevated-temperature curing, paste samples were demoulded and stored at $25 \pm 2^{\circ} \mathrm{C}$ and $65 \pm 5 \%$ relative humidity until testing. The compressive strength of the alkali-activated fly ash cement pastes was tested according to EN 196-1 (BSI, 2005). The test results reported here are the arithmetic means of six compressive strength values.

\section{Temperature development}

During the first part of the temperature development test, alkali-activated fly ash cement pastes with different sodium oxide contents were cast into a set of six plastic moulds according to EN 196-1 (BSI, 2005). The total paste volume was 4.61. The pastes with different sodium oxide contents were cured separately. Moulds were placed in an oven at $60^{\circ} \mathrm{C}$ immediately after casting. T-type thermocouples were embedded into the cores of moulds during casting and two thermocouples measured the temperature in the oven. Temperature development in the sample cores was recorded at $1 \mathrm{~min}$ intervals for the $24 \mathrm{~h}$ of elevated-temperature curing using a datalogger (Graphtec, Japan).

In the second part of the test, moulds of different sizes, made of metal and plastic were used. Alkali-activated fly ash cement pastes with $9 \%, 12 \%$ and $15 \%$ sodium oxide were studied. Core temperature development of the pastes with $3 \%$ and $6 \%$ sodium oxide was not investigated due to the results obtained in the first part of the test. Each of the three pastes was cast into a set of plastic and metal moulds (one of each) $-150 \mathrm{~mm}$ and $100 \mathrm{~mm}$ cubes and $40 \times 40 \times 160 \mathrm{~mm}$ prisms. The total volume of each mix was $10 \cdot 21$. K-type thermocouples were placed in the core of each mould. All six moulds for each paste sample were placed in an oven at $60^{\circ} \mathrm{C}$ and the temperature development in sample cores was recorded for $24 \mathrm{~h}$.

The oven used in this work (not equipped with a cooling system) had a net volume of $202 \cdot 51$. The ratio between paste volume and oven volume was constant at about 0.023 and 0.050 for the first and second parts of the experiment respectively.

\section{Initial shrinkage}

The alkali-activated fly ash cement pastes were studied in situ for volume changes during elevated-temperature curing in the oven. The shrinkage cone method for measuring shrinkage (Eppers and Müller, 2010) was adapted to measure volume changes of the alkali-activated fly ash cement pastes during the $24 \mathrm{~h} 60^{\circ} \mathrm{C}$ curing. A Micro Epsilon optoNCDT 1700 laser optical sensor with a measuring range of $2 \mathrm{~mm}$ was used. All components of the measuring equipment were preheated to $60^{\circ} \mathrm{C}$ before the test. The raw materials (fly ash and sodium hydroxide solution) were kept in a controlled-environment room $\left(25 \pm 2^{\circ} \mathrm{C}\right.$ and $65 \pm 5 \%$ relative humidity) for at least $24 \mathrm{~h}$ before the test.

Alkali-activated fly ash cement paste was cast into a coneshaped aluminium mould that was lined with a removable plastic cone to prevent direct contact between the metallic surface and the paste, which could result in a reaction between

\begin{tabular}{|c|c|c|c|c|c|c|c|}
\hline \multirow[t]{2}{*}{ Paste } & \multirow{2}{*}{$\begin{array}{c}\text { Sodium oxide } \\
\text { concentration: \% }\end{array}$} & \multirow[t]{2}{*}{$w / s$} & \multirow{2}{*}{$\begin{array}{c}\text { Curing } \\
\text { temperature: }{ }^{\circ} \mathrm{C}\end{array}$} & \multirow{2}{*}{$\begin{array}{c}\text { Curing } \\
\text { duration: } h\end{array}$} & \multicolumn{3}{|c|}{ Materials content: $\mathrm{kg} / \mathrm{m}^{3}$} \\
\hline & & & & & Fly ash & Sodium hydroxide & Water \\
\hline $\mathrm{Na3}$ & 3 & $0 \cdot 20$ & 60 & 24 & 1544 & 60 & 305 \\
\hline $\mathrm{Na} 6$ & 6 & $0 \cdot 20$ & 60 & 24 & 1527 & 118 & 297 \\
\hline Na9 & 9 & $0 \cdot 20$ & 60 & 24 & 1500 & 174 & 288 \\
\hline $\mathrm{Na} 12$ & 12 & $0 \cdot 20$ & 60 & 24 & 1469 & 228 & 278 \\
\hline $\mathrm{Na} 15$ & 15 & $0 \cdot 20$ & 60 & 24 & 1438 & 278 & 268 \\
\hline
\end{tabular}

Table 2. Mix designs and curing conditions of alkali-activated fly ash cement pastes 
the alkali and aluminium of the mould. The plastic cone also ensured that adhesion of the alkali-activated fly ash cement paste to the metal surface would not influence the readings. A vibrating table was used for compaction. After compaction, the mould with paste was weighed $\left(m_{1}\right)$. A reflector made out of light white plastic (to prevent its sinking into the fresh sample due to gravity) was embedded onto the paste surface. The initial height of the sample, $H$, was calculated from

1. $H=H_{\mathrm{m}}-H_{\mathrm{t}}-H_{\mathrm{r}}$

in which $H_{\mathrm{m}}$ is the depth of the empty cone mould (m), $H_{\mathrm{t}}$ is the distance from the top of the mould to the reflector placed on the paste surface (m) and $H_{\mathrm{r}}$ is the thickness of the reflector (m). The initial height was used as the reference length for calculating the initial shrinkage.

The mould with paste was placed into the oven underneath the sensor so that the laser beam was reflected by the plastic disc. The laser sensor was adjusted to have a maximum range and measurements were started as soon as the oven was closed. The whole process from adding activator solution to the fly ash to the first displacement measurement took $5-7 \mathrm{~min}$. The relative displacement was recorded by the datalogger at $10 \mathrm{~s}$ intervals for $24 \mathrm{~h}$.

After elevated-temperature curing, the mould with paste was weighed once again $\left(m_{2}\right)$ and the total mass loss was calculated as a percentage from

2. $L_{\mathrm{w}}=\frac{m_{1}-m_{2}}{m_{1}-m_{\mathrm{m}}} 100$

where $m_{1}$ is the mass of the mould with paste before elevatedtemperature curing $(\mathrm{g}), m_{2}$ is the mass of the mould with sample after elevated-temperature curing $(\mathrm{g})$ and $m_{\mathrm{m}}$ is the mass of the empty mould (g).

Initial shrinkage of the sample was calculated according to

3. Initial shrinkage $=\frac{H_{i}-H_{0}}{H}$

where $H_{i}$ is the laser reading at time $i(\mu \mathrm{m}), H_{0}$ is the initial laser reading $(\mu \mathrm{m})$ and $H$ is the initial height of the sample (m), calculated according to Equation 1.

\section{Results and discussion}

\section{Preliminary tests}

The average compressive strengths and standard deviations (error bars) of the alkali-activated fly ash cement pastes with different sodium oxide contents are shown in Figure 1. The figure shows that the compressive strength of the pastes was

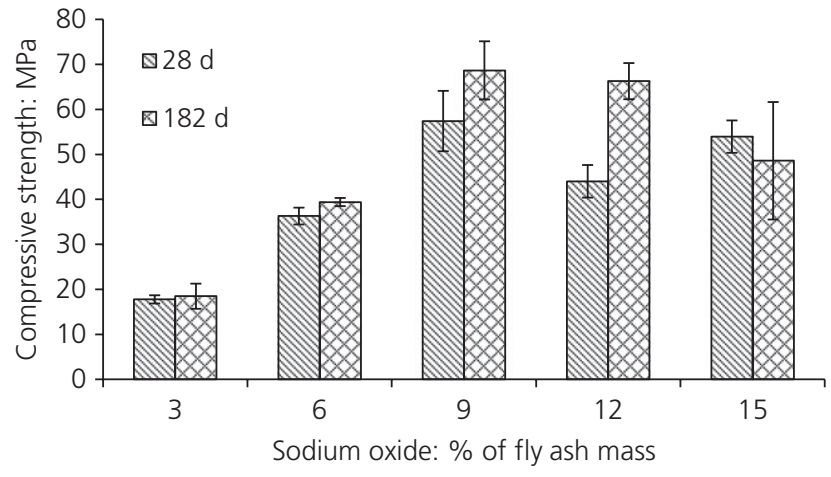

Figure 1. Effect of sodium oxide content on the compressive strength development of alkali-activated fly ash cement paste

strongly affected by sodium oxide content. An increase in sodium oxide up to $9 \%$ of fly ash mass led to an increase in compressive strength, but a further increase resulted in a decreased compressive strength. These strength results are in agreement with previous research (Shekhovtsova et al., 2014). The strength decrease phenomenon was an incitement to investigate the processes occurring during elevated-temperature curing of alkali-activated fly ash cement pastes.

\section{Temperature development}

The effect of alkali concentration (sodium oxide content) on the core temperature development of the alkali-activated fly ash cement pastes during elevated-temperature curing at $60^{\circ} \mathrm{C}$ (the first part of the test) is shown in Figure 2.

Figure 2 clearly shows that temperature inside the sample cores increased with an increase in sodium oxide content. The core temperature of sample $\mathrm{Na} 3$ did not differ from the oven temperature, being constant at about $60^{\circ} \mathrm{C}$ throughout the test. The maximum temperatures of pastes $\mathrm{Na} 6, \mathrm{Na} 9, \mathrm{Na} 12$ and $\mathrm{Na} 15$ were $62 \cdot 8^{\circ} \mathrm{C}, 68 \cdot 3^{\circ} \mathrm{C}, 71 \cdot 3^{\circ} \mathrm{C}$ and $68 \cdot 2^{\circ} \mathrm{C}$ respectively. The time of appearance of the maximum temperature was also affected by sodium oxide content: the peak temperatures for pastes $\mathrm{Na} 6, \mathrm{Na} 9, \mathrm{Na} 12$ and Na15 were observed after $8.7 \mathrm{~h}, 8.9 \mathrm{~h}$, $12 \cdot 2 \mathrm{~h}$ and $15 \cdot 0 \mathrm{~h}$ respectively. Thus the alkali activation reaction is delayed with an increase in sodium hydroxide concentration, but notably a $9 \%$ sodium oxide concentration (Na9) did not delay the activation process when compared with a $6 \%$ concentration (Na6). Alonso and Palomo (2001a) reported a lower rate of polymer formation with an increase in activator concentration. They noted that high activator concentrations produce a high $\mathrm{pH}$ in the liquid phase and anionic forms of silicate are more favoured, delaying polymerisation. Another observation from Figure 2 is that the pastes with lower alkali contents had narrower temperature humps than those of samples Na12 and Na15. Thus, pastes with high alkali contents were exposed to temperatures higher than $60^{\circ} \mathrm{C}$ for longer than the other pastes, which should affected their microstructure. 

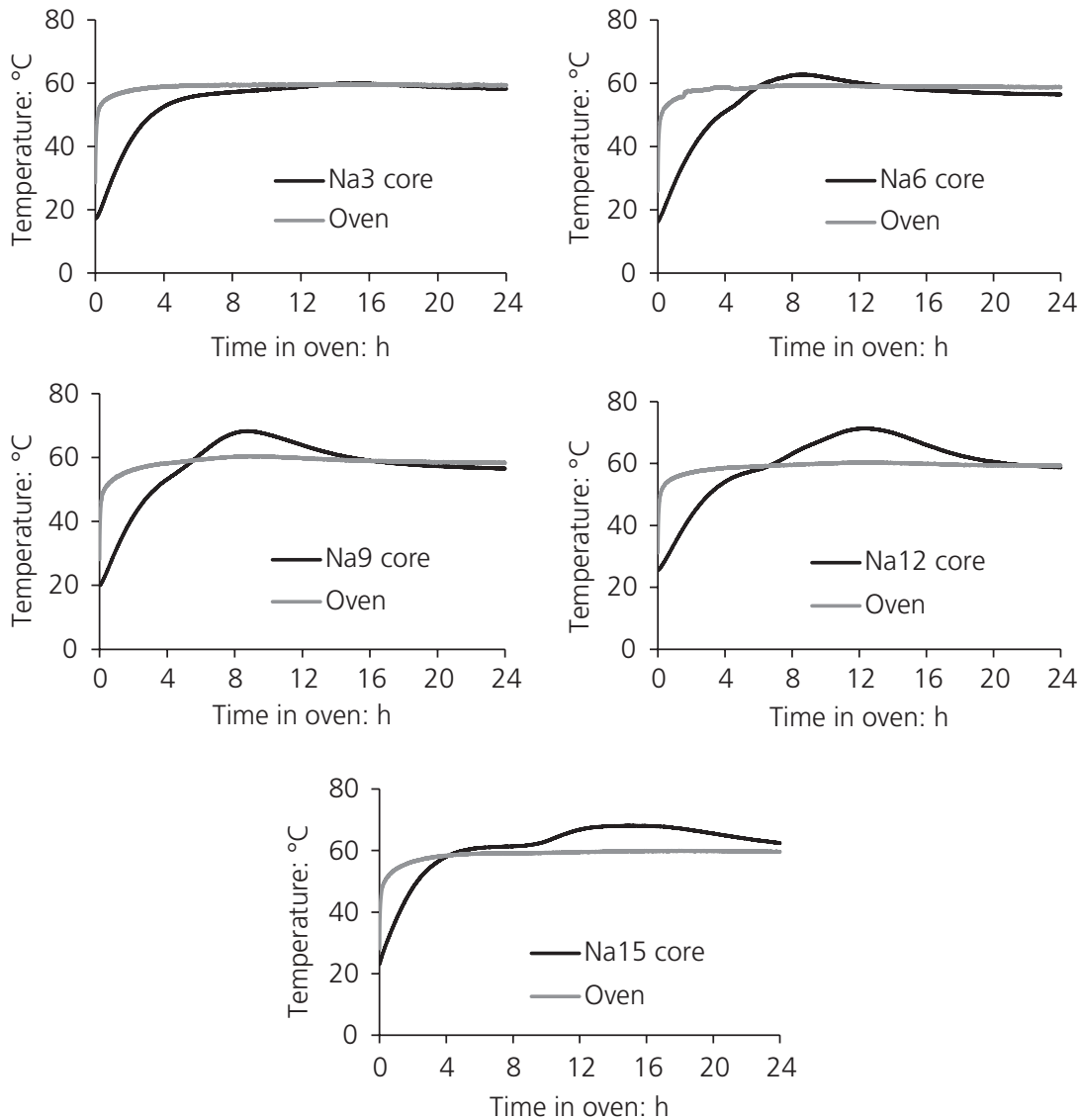

Figure 2. Core temperature development in alkali-activated fly ash cement pastes with different sodium oxide contents during elevated-temperature curing

Results from the second part of the temperature development test for alkali-activated fly ash cement pastes with $9 \%, 12 \%$ and $15 \%$ sodium oxide are shown in Figure 3. Table 3 lists the peak temperatures $\left(T_{\mathrm{p}}\right)$, the times of the appearance of peak temperature after the start of elevated-temperature curing $\left(t_{\mathrm{p}}\right)$ and the maximum temperature differences $\left(D_{\max }\right)$ between the sample core and the oven.

Several trends can be observed from Figure 3. The first trend is that the maximum core temperature was higher when the pastes were cured in plastic moulds rather than metal moulds regardless of the sodium oxide content of the pastes. The difference in maximum temperature became more prominent with an increase in the mould (sample) size. The trend can be explained by the differences in thermal conductivity properties of the mould materials (Table 4). Plastic moulds are less conductive, providing more insulation and thus preserving the heat emitted during the alkali activation process more effectively than metal moulds. Hence peak temperatures are higher in plastic moulds. This effect must be taken into account because excessive heat can damage the paste microstructure or it can be effectively used for self-curing of alkali-activated fly ash cements, thus decreasing the curing temperature/energy consumption required during elevated-temperature curing.

The second trend is the time of appearance of the peak temperature. For the prisms and the $100 \mathrm{~mm}$ cube moulds, the peak appeared earlier for plastic moulds compared with metal moulds. The reverse can be seen for the case of $150 \mathrm{~mm}$ cube moulds. The difference in the trend between the different mould sizes is again governed by the thermal conductivity of the mould materials. In the case of the prisms and $100 \mathrm{~mm}$ moulds, plastic preserves the heat emitted during alkali activation, which accelerates the process, and the temperature inside the samples thus reaches the maximum value earlier in comparison with metal moulds. As mentioned, the reverse pattern can be seen for the $150 \mathrm{~mm}$ moulds. Before intensive alkali activation takes place, a certain amount of energy must be transferred to activate the system, and this activation energy increases with an increase in sample size. At the initial stage, compared with the metal moulds, the plastic moulds decrease the energy flux transferred from the oven environment to the 

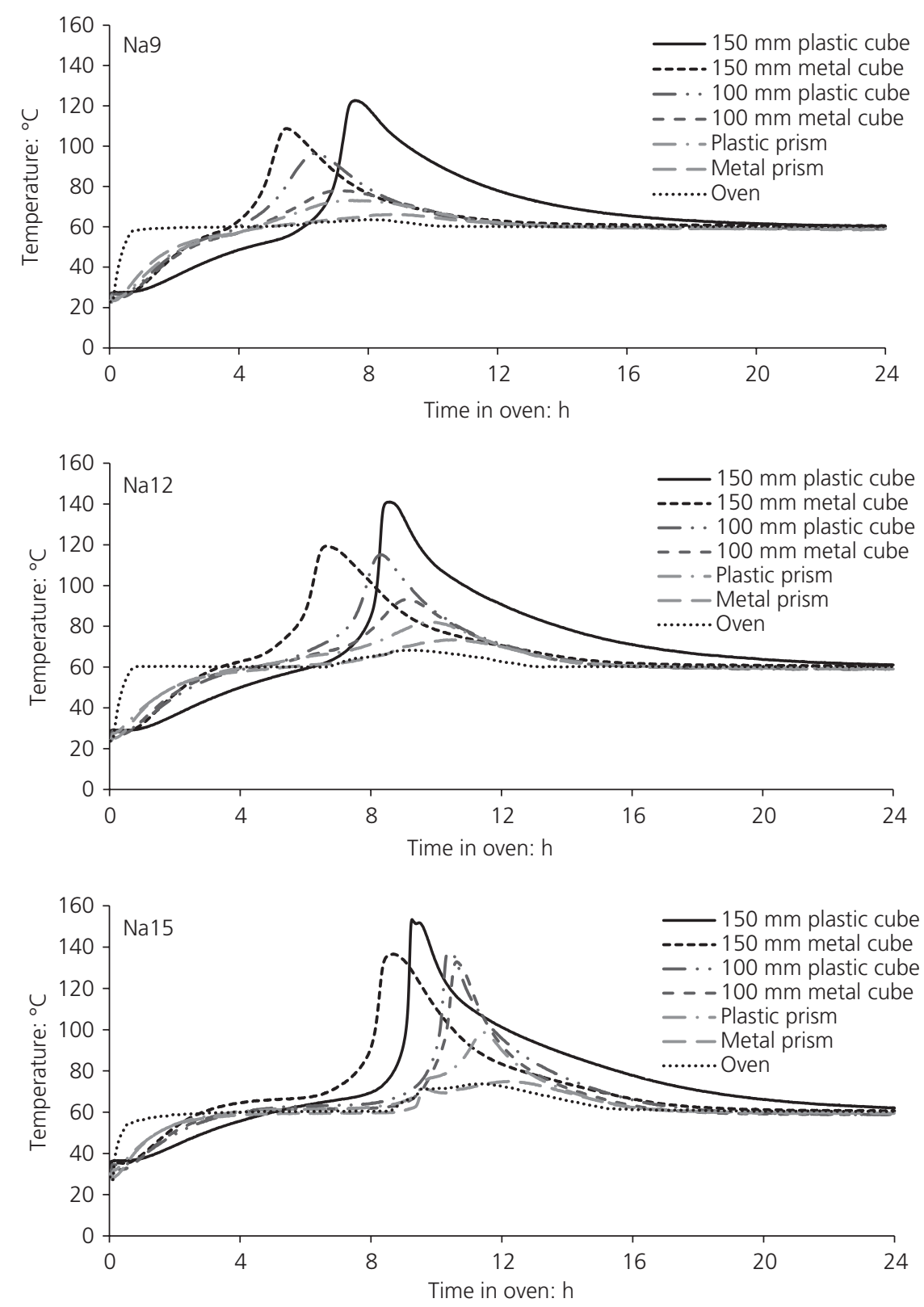

Figure 3. Influence of mould size and material on the temperature profiles of alkali-activated fly ash cement pastes with different sodium oxide contents during elevated-temperature curing

paste sample. This factor does not play a crucial role in the case of prisms and $100 \mathrm{~mm}$ cube moulds because the ratio of the open area (top of moulds) to the total volume is much higher in comparison with the $150 \mathrm{~mm}$ moulds. The trend is therefore influenced by both mould size and material. It is very important to note that the time of appearance of the peak temperature is affected by alkali concentration. The time of maximum temperature appearance increases with an increase in alkali concentration from $9 \%$ to $15 \%$ sodium oxide, which is in good correlation with the results of Alonso and Palomo (2001a). This was found to be the case for all types of moulds, regardless of their size or material. Therefore, an increased alkali content delays the alkali activation process.

The third trend from Figure 3 is that the maximum core temperature inside the paste samples increased with an increase in sample size and alkali content. The lowest peak temperature corresponded to the metal prism moulds, with values of 


\begin{tabular}{|c|c|c|c|c|c|c|c|c|c|}
\hline \multirow[t]{2}{*}{ Mould/oven } & \multicolumn{3}{|c|}{ Na9 } & \multicolumn{3}{|c|}{$\mathrm{Na} 12$} & \multicolumn{3}{|c|}{$\mathrm{Na} 15$} \\
\hline & $T_{\mathrm{p}}:{ }^{\circ} \mathrm{C}$ & $t_{\mathrm{p}}: \min$ & $D_{\text {max }}:{ }^{\circ} \mathrm{C}$ & $T_{\mathrm{p}}:{ }^{\circ} \mathrm{C}$ & $t_{p}: \min$ & $D_{\text {max }}:{ }^{\circ} \mathrm{C}$ & $T_{\mathrm{p}}:{ }^{\circ} \mathrm{C}$ & $t_{p}: \min$ & $D_{\text {max }}:{ }^{\circ} \mathrm{C}$ \\
\hline $150 \mathrm{~mm}$ metal cube & $108 \cdot 7$ & 327 & $47 \cdot 9$ & $119 \cdot 3$ & 397 & $58 \cdot 9$ & $136 \cdot 7$ & 521 & $74 \cdot 6$ \\
\hline $150 \mathrm{~mm}$ plastic cube & $122 \cdot 7$ & 455 & $59 \cdot 0$ & $141 \cdot 0$ & 515 & $72 \cdot 7$ & $153 \cdot 4$ & 555 & $83 \cdot 0$ \\
\hline $100 \mathrm{~mm}$ metal cube & $78 \cdot 0$ & 422 & $15 \cdot 1$ & $93 \cdot 2$ & 543 & $24 \cdot 9$ & $132 \cdot 9$ & 637 & $60 \cdot 5$ \\
\hline $100 \mathrm{~mm}$ plastic cube & $96 \cdot 3$ & 378 & $33 \cdot 9$ & $115 \cdot 0$ & 496 & $48 \cdot 6$ & $137 \cdot 1$ & 621 & $65 \cdot 0$ \\
\hline Metal prism & $66 \cdot 2$ & 528 & 3.9 & $73 \cdot 4$ & 620 & $7 \cdot 2$ & 74.9 & 731 & $3 \cdot 4$ \\
\hline Plastic prism & $73 \cdot 1$ & 447 & $10 \cdot 1$ & $82 \cdot 1$ & 587 & $14 \cdot 4$ & $98 \cdot 7$ & 686 & $27 \cdot 0$ \\
\hline Oven & $63 \cdot 7$ & 473 & - & $68 \cdot 3$ & 541 & - & $71 \cdot 7$ & 683 & - \\
\hline
\end{tabular}

Table 3. Maximum temperature $\left(T_{\mathrm{p}}\right)$, time of appearance of maximum temperature $\left(t_{\mathrm{p}}\right)$ and maximum temperature difference $\left(D_{\max }\right)$ between sample core and oven

\begin{tabular}{lcccc}
\hline Material & Density: $\mathrm{kg} / \mathrm{m}^{3}$ & Specific heat capacity: J/(kg.K) & Thermal conductivity: W/(m.K) & Thermal diffusivity: $10^{-6} \mathrm{~m}^{2} / \mathrm{s}$ \\
\hline Metal & 7850 & 452 & 40 & $11 \cdot 27$ \\
Plastic & 1160 & 1700 & 0.28 & $0 \cdot 14$
\end{tabular}

Table 4. Mould material properties

$66 \cdot 2^{\circ} \mathrm{C}, 73.4^{\circ} \mathrm{C}$ and $74.9^{\circ} \mathrm{C}$ for pastes $\mathrm{Na} 9, \mathrm{Na} 12$ and $\mathrm{Na} 15$ respectively. For the $150 \mathrm{~mm}$ plastic cube moulds, the temperatures for $\mathrm{Na} 9, \mathrm{Na} 12$ and $\mathrm{Na} 15$ reached $122.7^{\circ} \mathrm{C}, 141.0^{\circ} \mathrm{C}$ and $153.4^{\circ} \mathrm{C}$ respectively. The significantly increased amount of heat released during the alkali activation process by the pastes with alkali content higher than $9 \%$ sodium oxide can be seen not only in the maximum temperatures reached in the paste samples but also by the temperature developed in the oven during elevated-temperature curing. The temperature inside the oven changed for a period of time due to the heat emitted, reaching peaks of $63^{\circ} \mathrm{C}, 68^{\circ} \mathrm{C}$ and $72^{\circ} \mathrm{C}$ respectively for $\mathrm{Na} 9$, $\mathrm{Na} 12$ and $\mathrm{Na} 15$. This is because the ratio between paste volume and oven volume was higher than in the first part of the temperature development test and the oven was not equipped with a cooling device.

High temperatures attained in a sample core lead to significant temperature differences between the sample core and the oven (Table 3), meaning that free water will boil. This boiling water will produce vapour, resulting in a build-up of pressure inside the material microstructure causing internal stresses and thus leading to possible loss in the mechanical performance of the alkali-activated fly ash cement pastes due to the formation of microstructural defects such as microcracks as observed in previous research (Shekhovtsova et al., 2014).

In general, the temperature difference between sample and oven was higher for the larger moulds made out of plastic, and increased with an increase in alkali content (Table 3). Even assuming that the surface temperature of the sample is the same as the oven temperature at any time, exact values of the stress induced by the temperature differences (Table 3) could not be calculated due to lack of data regarding the thermal expansion coefficient and elastic modulus of the alkali-activated fly ash cement pastes. Notably though, an alkali content higher than $9 \%$ sodium oxide caused considerably higher temperature differences between the sample core and oven. The internal stresses due to such temperature differences might be higher than the pastes can withstand, especially taking into account the slower polymerisation process (Alonso and Palomo, 2001a) responsible for strength development, leading to the formation of microcracks and thus loss of material performance (Shekhovtsova et al., 2014).

The temperature development test showed that alkali-activated fly ash cement pastes may experience a significant rise in core temperature, which is dependent on the ratio of paste volume to oven volume, mould size, alkali concentration and mould material. Researchers should thus take into account possible temperature increases in sample cores and in curing ovens as excessive temperature can affect material performance.

\section{Initial shrinkage}

Shrinkage strains might also lead to crack formation, and so an in situ evaluation of volume changes during elevated-temperature curing was performed for the alkali-activated fly ash cement pastes with different sodium oxide contents.

In this test, initial shrinkage does not necessary represent the amount of water evaporated during elevated-temperature 
curing because, along with volume changes due to water evaporation, chemical shrinkage and thermal movements are also present. The initial shrinkage of the alkali-activated fly ash cement pastes during elevated-temperature curing at $60^{\circ} \mathrm{C}$ is shown in Figure 4, where each curve represents an average of two measurements.

Figure 4 shows that shrinkage during the first $24 \mathrm{~h}$ of elevatedtemperature curing strongly depended on sodium oxide content. The maximum initial shrinkage of paste $\mathrm{Na} 3$ was almost $3300 \mu \varepsilon$, whereas $\mathrm{Na} 6, \mathrm{Na} 9, \mathrm{Na} 12$ and $\mathrm{Na} 15$ showed initial shrinkages of $3800,4300,4700$ and $5200 \mu \varepsilon$ respectively. As shown in Figure 5, there is a linear relationship between sodium oxide content and maximum initial shrinkage, with a higher sodium oxide content resulting in higher initial shrinkage. The figure also shows that the maximum shrinkage rate is also a function of sodium oxide content, decreasing with sodium oxide content increasing from $3 \%$ to $15 \%$ of fly ash mass.

The mass loss during elevated-temperature curing for mixtures with different sodium oxide concentrations is shown as a

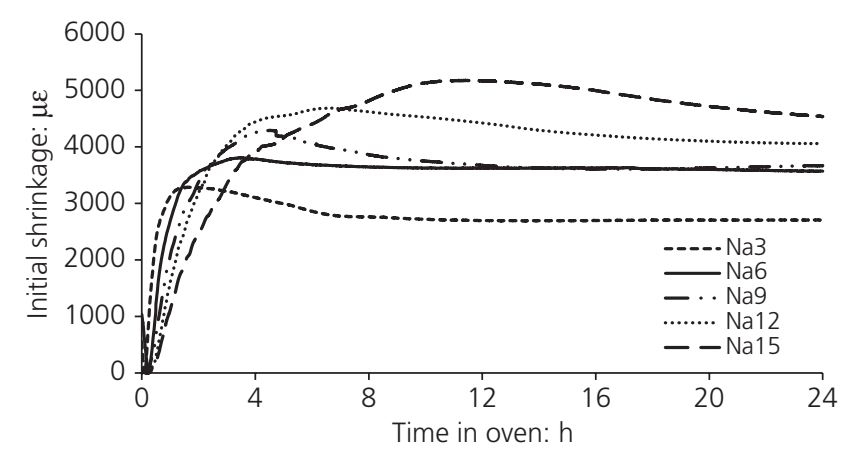

Figure 4. Initial shrinkage of alkali-activated fly ash cement pastes with different sodium oxide contents during elevated-temperature curing at $60^{\circ} \mathrm{C}$ for $24 \mathrm{~h}$

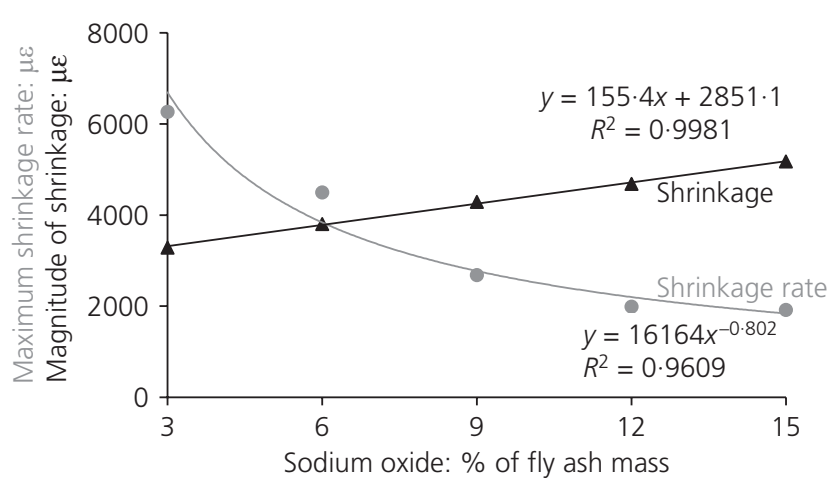

Figure 5. Maximum shrinkage rate and shrinkage magnitude versus sodium oxide content for alkali-activated fly ash cement pastes

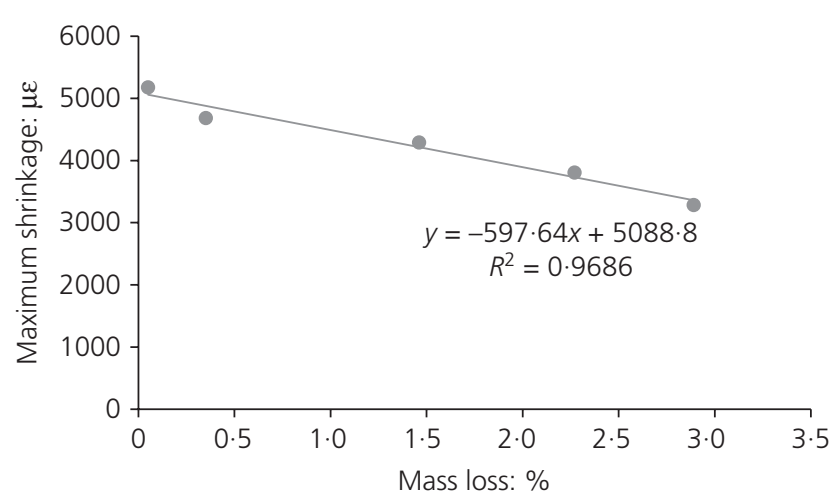

Figure 6. Mass loss versus maximum shrinkage for alkali-activated fly ash cement pastes

function of maximum shrinkage in Figure 6: samples that experienced more mass loss showed less shrinkage. It seems that the dominating factor affecting initial shrinkage is chemical in nature. For example, sample $\mathrm{Na} 3$ did not produce much reaction product (Shekhovtsova et al., 2014) and the major part of its initial shrinkage can be related to evaporated water. In contrast, Na15 did not lose any mass during elevated-temperature curing, but it did have the highest shrinkage value; this is because more fly ash particles were dissolved in the high alkaline solution, causing chemical contraction.

\section{Conclusions}

The following conclusions can be drawn from the results obtained in this study.

Oven temperature can be affected by the heat released during the alkali activation process if the oven is not equipped with a cooling system and the ratio of paste volume to oven volume exceeds a certain value.

- The core temperature of alkali-activated fly ash cement pastes increases significantly with increases in sodium oxide content and mould size. The mould material also influences paste core temperature.

- An excessive amount of sodium oxide not only inhibits the alkali activation process, which can be seen in the delayed core temperature development shown in this study, but also increases internal stresses induced by the rise in sample core temperature and the initial shrinkage of the alkaliactivated fly ash cement pastes. These internal stresses can weaken the structure of the material and result in a decrease in compressive strength, as observed by many researchers when alkali concentration exceeded a certain threshold. The magnitude of internal stresses significantly increases for sodium oxide contents higher than $9 \%$ of fly ash mass.

The results of this research show that more attention should be paid to the conditions and processes occurring during 
elevated-temperature curing of alkali-activated materials. Higher than intended temperatures might lead to unexpected results and could be the reason for material performance loss. Further research should be carried out to investigate the initial shrinkage mechanism and the processes occurring during elevated-temperature curing of alkali-activated materials.

\section{REFERENCES}

Alonso S and Palomo A (2001a) Alkaline activation of metakaoline and calcium hydroxide mixtures: influence of temperature, activator concentration and solids ratio. Materials Letters 47(1-2): 55-62.

Alonso S and Palomo A (2001b) Calorimetric study of alkaline activation of calcium hydroxide-metakaoline solid mixtures. Cement and Concrete Research 31(1): 25-30.

Atiş CD (2002) Heat evolution of high-volume fly ash concrete. Cement and Concrete Research 32(5): 751-756.

Atiş CD, Bilim C, Çelik Ö and Karahan O (2009) Influence of activator on the strength and drying shrinkage of alkali-activated slag mortar. Construction and Building Materials 23(1): 548-555.

Bakharev T (2005) Durability of geopolymer material in sodium and magnesium sulfate solutions. Cement and Concrete Research 35(6): 1233-1246.

Bakharev T, Sanjayan JG and Cheng YB (1999) Alkali activation of Australian slag cements. Cement and Concrete Research 29(1): 113-120.

Bernal SA and Provis JL (2014) Durability of alkali-activated materials: progress and perspectives. Journal of the American Ceramic Society 97(4): 997-1008.

Brough AR and Atkinson A (2002) Sodium silicate-based, alkali-activated slag mortars Part 1 . Strength, hydration and microstructure. Cement and Concrete Research 32(6): 865-879.

BSI (2005) BS EN 196-1:2005: Methods of testing cement part 1: determination of strength. BSI, London, UK.

Chindaprasirt P, Jaturapitakkul C, Chalee W and Rattanasak U (2009) Comparative study on the characteristics of fly ash and bottom ash geopolymers. Waste Management 29(2): 539-543.

Chithiraputhiran S and Neithalath N (2013) Isothermal reaction kinetics and temperature dependence of alkali activation of slag, fly ash and their blends. Construction and Building Materials 45: 233-242.

Criado M, Fernández-Jiménez A, de la Torre AG, Aranda MAG and Palomo A (2007) An XRD study of the effect of the $\mathrm{SiO}_{2} / \mathrm{Na}_{2} \mathrm{O}$ ratio on the alkali activation of fly ash. Cement and Concrete Research 37(5): 671-679.

Criado M, Fernández-Jiménez A, Sobrados I, Palomo A and Sanz $J$ (2012) Effect of relative humidity on the reaction products of alkali activated fly ash. Journal of the European Ceramic Society 32(11): 2799-2807.

Duxson P, Mallicoat SW, Lukey GC, Kriven WM and van Deventer JSJ (2007) The effect of alkali and Si/Al ratio on the development of mechanical properties of metakaolin-based geopolymers. Colloids and Surfaces A: Physiochemical and Engineering Aspects 292(1): 8-20.

Eppers S and Müller C (2010) The shrinkage cone method for measuring the autogenous shrinkage - an alternative to the corrugated tube method. Proceedings of International RILEM Conference on Use of Superabsorbent Polymers and Other New Additives in Concrete, Lyngby, Denmark, pp. 67-76.

Fernández-Jiménez A and Palomo A (2005) Composition and microstructure of alkali-activated fly ash. Effect of the activator. Cement and Concrete Research 35(10): 1984-1992.

Fernández-Jiménez A and Puertas F (1997) Alkali-activated slag cements: kinetic studies. Cement and Concrete Research 27(3): 359-368.

Ghosh K and Ghosh P (2012) Effect of synthesizing parameters on compressive strength of fly ash based geopolymer paste. International Journal of Structural and Civil Engineering 1(8): $1-11$.

Görhan G and Kürklü G (2014) The influence of the $\mathrm{NaOH}$ solution on the properties of the fly ash-based geopolymer mortar cured at different temperatures. Composites: Part B 58: 371-377.

He J, Jie Y, Zhang J, Yu Y and Zhang G (2013) Synthesis and characterization of red mud and rice husk ash-based geopolymer composites. Cement and Concrete Composites 37: 108-118.

Heah CY, Kamarudin H, Mustafa Al Bakri AM et al. (2013)

Kaolin-based geopolymers with various $\mathrm{NaOH}$ concentrations. International Journal of Minerals, Metallurgy and Materials 20(3): 313-322.

Hounsi AD, Lecomte-Nana GL, Djétéli G and Blanchart P (2013) Kaolin-based geopolymers: effect of mechanical activation and curing process. Construction and Building Materials 42: 105-113.

Ismail I, Bernal SA, Provis JL et al. (2013) Influence of fly ash on the water and chloride permeability of alkali-activated slag mortars and concretes. Construction and Building Materials 48: 1187-1201.

Lemougna PN, Chinje Melo UF, Delplancke MP and Rahier H (2014) Influence of the chemical and mineralogical composition on the reactivity of volcanic ashes during alkali activation. Ceramics International 40(1): 811-820.

McLellan BC, Williams RP, Lay J, van Riessen A and Corder GD (2011) Cost and carbon emissions for geopolymer pastes in comparison to ordinary Portland cement. Journal of Cleaner Production 19(9-10): 1080-1090.

Muñiz-Villareal MS, Manzano-Ramírez A, Sampieri-Bulbarela S et al. (2011) The effect of temperature on the geopolymerization process of a metakaolin-based geopolymer. Materials Letters 65(6): 995-998.

Najafi Kani E and Allahverdi A (2011) Investigating shrinkage changes of natural pozzolan based geopolymer cement paste. Iranian Journal of Materials Science and Engineering 8(3): 50-60. 
Palomo A, Grutzeck MW and Blanco MT (1999) Alkali-activated fly ashes: a cement for the future. Cement and Concrete Research 29(8): 1323-1329.

Papa E, Medri V, Landi E, Ballarin B and Miccio F (2014) Production and characterization of geopolymers based on mixed compositions of metakaolin and coal ashes. Materials and Design 56: 409-415.

Provis JL (2009) Activating solution chemistry for geopolymers. In Geopolymers. Structure, Processing, Properties and Industrial Application (Provis JL and van Deventer JSJ (eds)). Woodhead Publishing, Cambridge, UK, pp. $50-71$.

Provis JL (2013) Geopolymers and other alkali-activated materials: why, how and what? Materials and Structures 47(1-2): 11-25.

Puertas F, Martínez-Ramírez S, Alonso S and Vázquez T (2000) Alkali-activated fly ash/slag cements: strength behavior and hydration products. Cement and Concrete Research 30(10): 1625-1632.

Ridtirud C, Chindaprasirt P and Pimraksa K (2011) Factors affecting the shrinkage of fly ash geopolymers. International Journal of Minerals, Metallurgy and Materials 18(1): 100-104.

Shekhovtsova J, Kearsley EP and Kovtun M (2014) Effect of activator dosage, water-to-binder-solids ratio, temperature and duration of elevated temperature curing on the compressive strength of alkali-activated fly ash cement pastes. Journal of the South African Institution of Civil Engineering 56(3): 44-52.

Škvára F, Šlosar J, Bohunek J and Marková A (2003) Alkaliactivated fly ash geopolymeric materials. In Proceedings of 11th International Congress on the Chemistry of Cement: Cement's Contribution to the Development in the 21st Century, Durban, South Africa (Grieve G and Owens G (eds)) Durban, South Africa, pp. 1341-1350, CD-ROM. Somna K, Jaturapitakkul C, Kajitvichyanukul P and Chindaprasirt $\mathrm{P}$ (2011) $\mathrm{NaOH}$-activated ground fly ash geopolymer cured at ambient temperature. Fuel 90(6): 2118-2124.
Steveson M and Sagoe-Crentsil K (2005) Relationships between composition, structure and strength of inorganic polymers. Part 2 fly ash-derived inorganic polymers. Journal of Materials Science 40(16): 4227-4259.

Sukmak P, Horpibulsuk S and Shen SL (2013) Strength development in clay-fly ash geopolymer. Construction and Building Materials 40: 566-574.

Tarasov AS, Kearsley EP, Kolomatskiy AS and Mostert HF (2010) Heat evolution due to cement hydration in foamed concrete. Magazine of Concrete Research 62(12): 895-906.

Turner LK and Collins FG (2013) Carbon dioxide equivalent $\left(\mathrm{CO}_{2}\right.$-e) emissions: a comparison between geopolymer and OPC cement concrete. Construction and Building Materials 43: 125-130.

Van Deventer JSJ, Provis JL, Duxson P and Brice DG (2010) Chemical research and climate change as drivers in the commercial adoption of alkali activated materials. Waste and Biomass Valorization 1(1): 145-155.

Van Jaarsveld JGS and van Deventer JSJ (1999) Effect of the alkali metal activator on the properties of fly ash-based geopolymers. Industrial and Engineering Chemistry Research 38(10): 3932-3941.

Winnefeld F, Leemann A, Lucuk M, Svoboda P and Neuroth M (2010) Assessment of phase formation in alkali activated low and high calcium fly ashes in building materials. Construction and Building Materials 24(6): 1086-1093.

Yang KH, Song JK and Song KI (2013) Assessment of $\mathrm{CO}_{2}$ reduction of alkali-activated concrete. Journal of Cleaner Production 39: 265-272.

Zhang Z, Wang H, Provis JL et al. (2012) Quantitative kinetic and structural analysis of geopolymers. Part 1 . The activation of metakaolin with sodium hydroxide. Thermochimica Acta 539: 23-33.

Zhang Z, Provis JL, Wang H, Bullen F and Reid A (2013) Quantitative kinetic and structural analysis of geopolymers. Part 2. Thermodynamics of sodium silicate activation of metakaolin. Thermochimica Acta $\mathbf{5 6 5}$ : 163-171.

\section{WHAT DO YOU THINK?}

To discuss this paper, please submit up to 500 words to the editor at journals@ice.org.uk. Your contribution will be forwarded to the author(s) for a reply and, if considered appropriate by the editorial panel, will be published as a discussion in a future issue of the journal. 